\title{
THE GADGET GENERATION: BODY MASS INDEX AND DURATION OF PHYSICAL ACTIVITY AND SCREEN-VIEWING AMONG PRESCHOOLERS IN KUANTAN, PAHANG
}

\author{
Norashikin Mustafa, Roszanadia Rusali, Al-Hafizah A. Ramos, Jamilah Ghazali, and Nor Azwani Mohd \\ Shukri
}

Department of Nutrition Sciences, Kulliyyah of Allied Health Sciences, International Islamic University Malaysia, 25200 Kuantan, Pahang, Malaysia

Corresponding author: Dr. Nor Azwani Mohd Shukri

Email: norazwani@iium.edu.my

\begin{abstract}
Sedentary lifestyle due to physical inactivity and increased screen-viewing (SV) duration is one of the risk factors for childhood obesity. Thus, this study aimed to assess body mass index (BMI), SV and physical activity (PA) durations among children aged four-to-six years $(\mathrm{N}=284)$ attending kindergartens in urban and rural areas of Kuantan, Pahang. The SV and PA durations were estimated via a questionnaire completed by their parents. The preschoolers' height and weight were measured using a stadiometer and a digital weighing scale, respectively. The BMl-for-age status was interpreted using the CDC growth charts and cut-off points. A total of $37.8 \%$ of respondents were underweight, $16.7 \%$ overweight/obese, while the rest had normal BMI. Almost $90 \%$ of the children were using electronic gadgets. In addition, $89.8 \%$ of them recorded $>$ two hours/day of total SV duration, exceeding the international recommendation of <two hours/day of screen time and the Malaysian Dietary Guideline's recommendation of <two hours/day of sedentary activity. Only $49.8 \%$ (on weekdays) and $75.4 \%$ (on weekends) of the children met the recommended one hour/day of moderate PA by the WHO. There were no significant differences of BMI, SV and PA durations between urban and rural respondents. The preschoolers in Kuantan were largely found to exceed the recommended SV duration and only half of them met the recommended PA duration on most days. This suggests that intervention is needed to curb these obesity-inducing sedentary behaviours due to long SV duration and physical inactivity among preschoolers across urban and rural areas of the Pahang capital district.
\end{abstract}

Keywords: Screen-viewing, electronic gadget, childhood obesity, physical activity, BMI

\section{INTRODUCTION}

Childhood obesity is one of the most serious public health challenges globally. According to a report by the World Health Organization (WHO), the number of overweight or obese children aged under five years was reported to be over 38 million in 2017, increasing almost 30\% since $1990^{1}$. More alarmingly, almost half of the prevalence was reported to be in Asian region'. A similar trend was observed among Malaysian children aged six to 12 years among which the prevalence was shown to increase from $20.7 \%$ in 2002 to $26.4 \%$ in $2008^{2}$. According a systematic review, obesity in children may reflect the health condition in later life with the emergence of metabolic syndromes which include diabetes, hypertension, ischaemic heart disease and stroke ${ }^{3}$. Other than that, childhood obesity might also give a longlasting negative impact on children's body image, economic mobility, and self-esteem ${ }^{4}$

Physical inactivity among young children has been reported worldwide. In Canada, based on a guardian-reported physical activity (PA), almost half $(45 \%)$ of the preschool children did not meet the minimum guidelines of PA recommendation of 60 minutes daily for children aged from birth to 5 years ${ }^{5}$. Meanwhile, a systematic review on PA of
Asian school-aged children and adolescents (7-19 years old) measured subjectively (using questionnaires and diaries) and objectively (using accelerometers and heart rate monitors) found that less than $50 \%$ of samples reviewed met the minimum PA recommendation of 30 minutes, three days per week ${ }^{6}$. A recent infographic report by the National Health and Morbidity Survey 2017 identified that only $45 \%$ of Malaysian students were categorized as physically active. However, the percentage of physically active students was reduced as their age increased (primary school students $57 \%$ vs secondary school children $37.3 \%)^{7}$. Physical inactivity has also been identified as the one of the leading risk factors for global mortality, the concern which has led the WHO to introduce the Global Recommendation of Physical Activity for Health ${ }^{8}$. It is recommended that all healthy children and adolescents aged 5 to 17 years old should accumulate at least 60 minutes of moderate-to vigorous-intensity PA daily, most of which should be aerobic. In addition, vigorousintensity activities including those that strengthen muscle and bone should be incorporated, at least three times per week ${ }^{8}$. In Malaysia, a specific guideline for PA is included by the Ministry of Health Malaysia $(\mathrm{MOH})$ in the Malaysian Dietary Guidelines (MDG) for Children and Adolescents which suggests the accumulation 
of at least one hour of moderate intensity PA per day 9 .

Being sedentary or engaging in particularly long screen-viewing (SV) has been found to be related to low PA level ${ }^{10}$. The MDG for Children and Adolescents recommends that SV duration should be limited to not more than two hours a day? However, a cross-sectional study in Malaysia reported that a majority of children exceeded the SV recommendation up to 3.1 hours per day, where children from urban areas spend more time on screen viewing compared to children from rural areas $^{11}$. The long duration spent in front of screen would increase their sitting time during waking hours. This condition would contribute to their sedentary behaviour and the risk of becoming obese $^{12,13}$. Shorter sleep duration due to high SV duration is also one of the possible mechanisms positively associated with childhood obesity ${ }^{14}$. Studies also found that high SV duration, predominantly television (TV) viewing, could cause poor food habit which might lead to childhood obesity ${ }^{15-17}$. Television viewing time has been associated with lower consumption of fruits and vegetables, skipping breakfast at least once a week, eating fast food once a week and high consumption of sugary food and drinks ${ }^{15}$, 17-18. In addition, watching food advertisements on TV may promote high consumption of calorie-dense foods among children ${ }^{19-20}$. On the other hand, less time spent on TV watching is associated with better dietary quality among American children ${ }^{21}$.

Obesity in childhood is associated with serious health complications and an increased risk of premature onset of chronic illnesses ${ }^{3}$. Unfortunately, the increasingly urbanized and digitalized world is making physical activity less conducive. Children are becoming more sedentary which could contribute to gaining excess weight. Therefore, children in urban areas might have higher SV duration which lead to lower PA level and this situation would be associated with higher BMI values. However, studies on PA level and SV duration among preschool children in Malaysia are still very much needed. Thus, this study was conducted to assess the duration of PA and SV, and their potential association with BMI among preschoolers in urban and rural areas of Kuantan, Pahang.

\section{METHODS}

\section{Study area}

A cross-sectional study was conducted at 11 kindergartens of Taman Bimbingan Kanak-kanak (TABIKA) Jabatan Kemajuan Masyarakat (KEMAS) located in Kuantan, Pahang. Based on their locations, four TABIKA were categorized by KEMAS as rural while the rest were identified as urban.

\section{Study population}

The inclusion criteria for subjects to participate in this study were generally healthy children aged four to six years who were attending the selected TABIKA KEMAS at the time of data collection. This study obtained an ethical approval and permission from the International Islamic University Malaysia (IIUM) Ethics Committee (IREC) and the Pejabat KEMAS Daerah Kuantan.

\section{Sample size estimation}

The required sample size for the study was calculated based on two sample proportions by using the PS Power and Sample Size Calculation (Version 3.1) program. According a previous study $^{22}$, the prevalence of childhood obesity (overweight and obese) in urban area in Malaysia was 17\%. A sample size of 137 (including 10\% nonresponse rate) was needed for each of the urban and rural groups.

\section{Questionnaire}

A parent-administered questionnaire was constructed in Malay and consisted of three sections. Section A included the demographic data such as details of preschool children (name, birthday, age, gender, race, religion) and the parents/caretaker (age, race, occupation, religion, education level, household income, and self-reported parental height and weight). Section B included the PA data of the children based on involvement of PA at home, PA frequency on weekly basis, duration of PA daily, and activities during leisure time. Meanwhile, Section C included six multiple-choice-answer questions related to children's SV activities and an open-ended question on parents' opinion about the usage of electronic gadgets among children.

The questionnaire was pre-tested prior to the actual data collection. This was conducted among 20 staff of the Kulliyyah of Allied Health Sciences, IIUM. They comprised of academic and nonacademic staff with different educational background and were parents of preschool children. The findings of the pre-test demonstrated that the questionnaire was appropriate to be used for the actual research.

\section{Anthropometry measurements}

The body weight of the study participants was measured using a TANITA digital weighing scale, while height was measured using a SECA stadiometer. The BMI was calculated as weight (kg) divided by height squared $\left(\mathrm{m}^{2}\right)$, and the BMIfor-age status was assessed by using the Centers for Disease Control and Prevention (CDC) Growth Charts (2000). The BMI values were categorized as underweight $\left(<5^{\text {th }}\right.$ percentile), normal $\left(5^{\text {th }}\right.$ to $<85^{\text {th }}$ percentiles $)$, overweight $\left(85^{\text {th }}\right.$ to $<95^{\text {th }}$ percentile), and obese ( $\geq 95^{\text {th }}$ percentile $)^{23}$.

\section{Statistical analysis}

Variables were described as mean (standard deviation, SD) if they were continuous and normally distributed, median (interquartile range, IQR) if continuous but not normally distributed, or frequency (\%) if otherwise. The 
independent t-test was used to compare the mean BMI between children of rural and urban areas. The chi square test was used to find the association between two independent categorical variables. The difference was regarded as statistically significant at $95 \%$ confidence interval. All the data were analysed using IBM SPSS (Version 24.0).

\section{RESULTS}

A total of 284 participants completed the data based on the variables of interest and were included in the current study. The characteristics of the participants were stratified by urban/rural status and are presented in Table 1.

The mean age of the participants in this study was $4.4 \pm 0.6$ years. According to the demographic data of the parents, about half of them (48.4\%) were working in the non-government sector such as working with private companies or running their own businesses. Urban parents had significantly higher education level and household income compared to those from rural area.

The BMI classification of preschool children Based on the BMI classification, almost half of the study participants were categorized as having normal BMI (45.5\%). More than a third of the preschoolers were underweight $(37.8 \%)$, while $6.1 \%$ were overweight and $10.6 \%$ were obese. No significant difference was found with regards to the BMI status of the preschool children between the rural and urban areas.

Physical activity among preschool children The mean PA of preschool children during weekdays $(1.6 \pm 0.8$ hours/day) was significantly $(p<0.001)$ lower than during weekends $(2.0 \pm 0.8$ hours/day). Overall, there were $49.2 \%$ and $75.4 \%$ of the preschool children who met the recommendation of PA of more than one hour per day during weekdays and weekends, respectively

There was a higher number of preschool children who met the recommended one hour of PA daily in rural than in urban areas. Figure 1 illustrates the activities engaged by preschool children during free time (when they were not involved in any PA). Based on parents' reports, generally, $90 \%$ of preschool children spent their free time by watching TV followed by using gadgets, sleeping, reading, and doing other activities (playing puzzle, colouring, listening to music, etc.).

Table 1: The characteristics of study participants stratified by locations $(\mathrm{N}=\mathbf{2 8 4})$

\begin{tabular}{|c|c|c|c|c|}
\hline \multirow[b]{2}{*}{ Variables } & \multirow[b]{2}{*}{$\begin{array}{c}\text { TOTAL } \\
(\mathrm{N}=284)\end{array}$} & \multicolumn{2}{|c|}{ Areas } & \multirow[b]{2}{*}{ P-value } \\
\hline & & $\begin{array}{c}\text { Urban } \\
(\mathrm{N}=139)\end{array}$ & $\begin{array}{c}\text { Rural } \\
(N=145)\end{array}$ & \\
\hline Age, mean (SD) & $4.36(0.6)$ & $4.26(0.7)$ & $4.50(0.5)$ & $0.01^{2}$ \\
\hline Gender, n (\%) & & & & $0.36^{1}$ \\
\hline Boys & $136(48.0)$ & $63(45.4)$ & $73(50.4)$ & \\
\hline Girls & $148(52.0)$ & $76(54.6)$ & $72(49.6)$ & \\
\hline BMI, mean (SD) & $15.12(2.6)$ & $15.06(2.6)$ & $15.18(2.6)$ & $0.70^{2}$ \\
\hline Underweight, n (\%) & 107(37.8) & $47(39.5)$ & $46(36.2)$ & $0.43^{1}$ \\
\hline Normal, n (\%) & $129(45.5)$ & $56(47.1)$ & $56(44.1)$ & \\
\hline Overweight, n (\%) & $17(6.1)$ & $4(3.4)$ & 11(8.7) & \\
\hline Obese, n (\%) & $31(10.6)$ & $12(10.1)$ & 14(11.0) & \\
\hline Parents' occupation & & & & $0.03^{1}$ \\
\hline Government & $90(31.7)$ & $55(39.5)$ & $35(24.4)$ & \\
\hline Non-government & 137(48.4) & $62(44.5)$ & $75(52.0)$ & \\
\hline Unemployed & $57(19.9)$ & $22(16.0)$ & $35(23.6)$ & \\
\hline Parent's education, n (\%) & & & & $<0.001^{1}$ \\
\hline Primary & $15(5.3)$ & $5(3.4)$ & $10(7.1)$ & \\
\hline Secondary & $194(68.3)$ & $82(58.8)$ & $105(72.2)$ & \\
\hline College/university & $75(26.4)$ & $42(437.8)$ & $30(15.7)$ & \\
\hline Household income, $\mathrm{n}(\%)$ & & & & $<0.001^{1}$ \\
\hline$<\mathrm{RM} 2,000$ & $163(57.3)$ & $56(40.3)$ & $106(73.2)$ & \\
\hline $\mathrm{RM} 2,000-4,000$ & $99(35.0)$ & $65(47.1)$ & $34(23.6)$ & \\
\hline$>\mathrm{RM} 4,000$ & $22(7.7)$ & $18(12.6)$ & $5(3.1)$ & \\
\hline Physical activity (Weekdays) & & & & $<0.001^{1}$ \\
\hline$<1$ hour & $137(48.4)$ & $81(58.6)$ & $60(41.1)$ & \\
\hline$>1$ hour & $147(49.2)$ & $58(41.4)$ & $85(58.9)$ & \\
\hline Physical activity (Weekends) & & & & $0.41^{1}$ \\
\hline$<1$ hour & $70(24.6)$ & $38(27.1)$ & $36(24.8)$ & \\
\hline$>1$ hour & $214(75.4)$ & $101(72.9)$ & $109(77.4)$ & \\
\hline
\end{tabular}

${ }^{1}$ Chi-square test; ${ }^{2}$ Independent t-test; RM - Ringgit Malaysia; BMI - Body mass index 


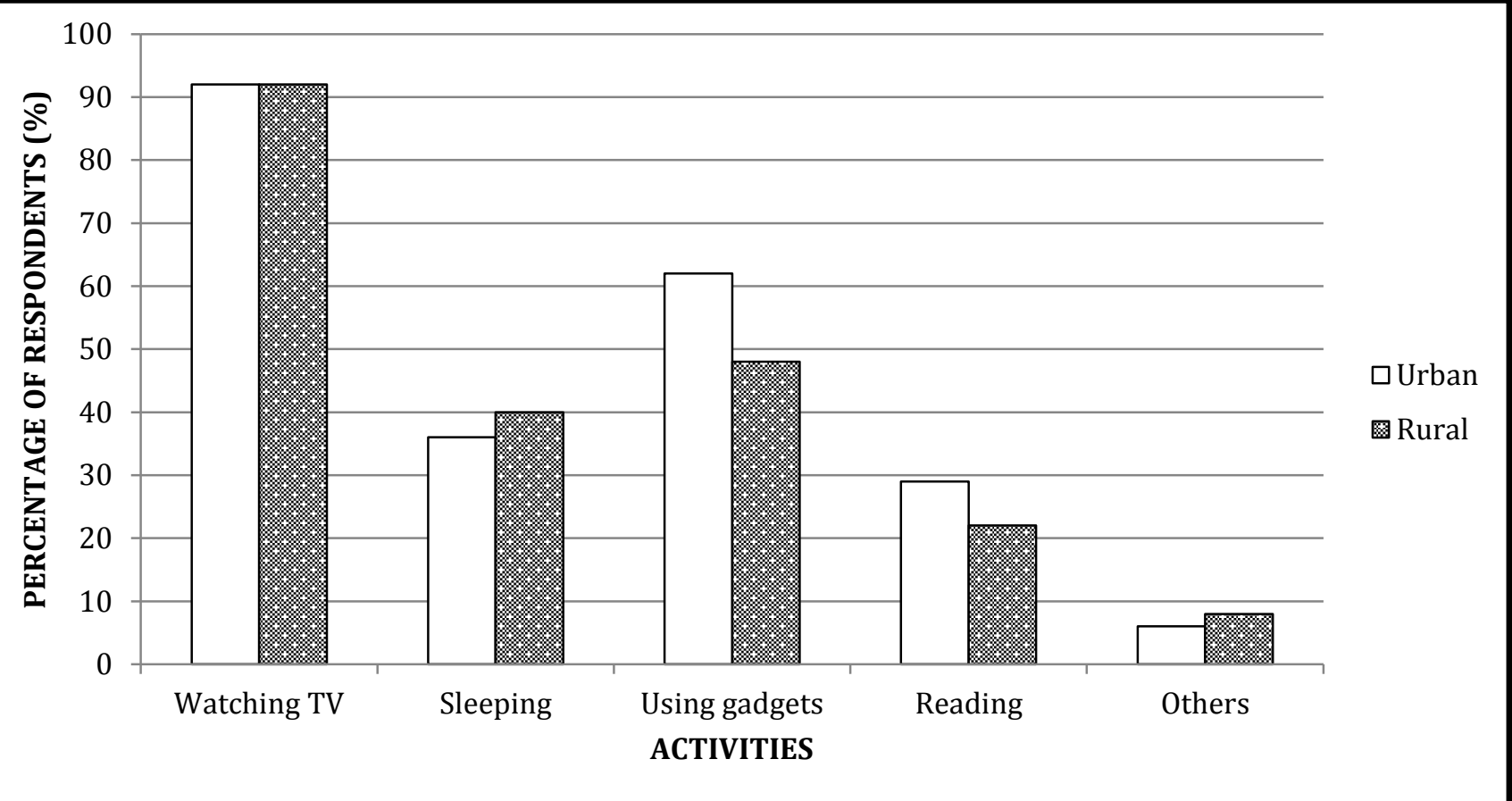

Figure 1: Sedentary activities engaged by preschool children in Kuantan during free time $(\mathrm{N}=\mathbf{2 8 4})$

Table 2: Screen-viewing activity among preschool children in Kuantan $(\mathrm{N}=284)$

\begin{tabular}{|c|c|c|c|c|}
\hline \multirow[b]{2}{*}{ Variables } & \multirow[b]{2}{*}{$\begin{array}{c}\text { TOTAL } \\
(\mathrm{N}=\mathbf{2 8 4})\end{array}$} & \multicolumn{2}{|c|}{ Areas } & \multirow[b]{2}{*}{ P-value ${ }^{1}$} \\
\hline & & Urban $(\mathrm{N}=139)$ & $\begin{array}{c}\text { Rural } \\
(\mathrm{N}=145)\end{array}$ & \\
\hline Gadget usage, n (\%) & & & & 0.55 \\
\hline Yes & $249(87.8)$ & $124(89.1)$ & $126(86.6)$ & \\
\hline No & $35(12.2)$ & $15(10.9)$ & 19(13.4) & \\
\hline Gadget usage duration, $\mathrm{n}$ (\%) & & & & 0.17 \\
\hline$<2$ hours & $243(85.6)$ & $100(72.3)$ & $112(77.2)$ & \\
\hline$>2$ hours & $41(14.4)$ & $39(16.0)$ & $33(9.4)$ & \\
\hline TV viewing duration $\mathrm{n}(\%)$ & & & & 0.80 \\
\hline$<2$ hours & $98(34.4)$ & $49(35.3)$ & $49(33.6)$ & \\
\hline$>2$ hours & $186(65.6)$ & $90(64.7)$ & $96(66.4)$ & \\
\hline $\begin{array}{l}\text { Total screen viewing } \\
\text { duration, } \mathrm{n}(\%)\end{array}$ & & & & 0.97 \\
\hline$<2$ hours & $29(10.2)$ & $14(10.1)$ & $15(10.2)$ & \\
\hline$>2$ hours & $255(89.8)$ & $125(89.9)$ & $130(89.8)$ & \\
\hline
\end{tabular}

\section{Screen-viewing activity among preschool} children

As demonstrated in Table 2, most of the preschool children (87.8\%) were using gadgets every day, with $14 \%$ of them spent $>2$ hours/day on this. No significant difference was detected between urban and rural areas. Parents were asked on the reasons of giving their children gadgets. The three most common reasons were parents felt that gadgets have educational benefits (58.1\%); parents wanted to fulfil their children's demand (47.2\%); and parents used gadgets to control their children's behaviors (46\%). On the other hand, $12.2 \%$ of parents did not allow their children to use gadgets. This was due to parents' belief that gadgets could give negative effects to their children; parents' preference to let their children play with conventional toys compared to using gadgets; and parents' financial limitation that hindered them from buying gadgets. In addition, more than half of the preschool children (65.5\%) were watching TV for $>2$ hours/day (Table 2). Again, no statistical difference was found between preschool children staying in rural and urban areas.

On average, 3.8 hours/day of total SV duration was reported among preschool children in the current study. A large majority $(89.8 \%)$ of them spent $>2$ hours/day on SV, with no significant difference between urban and rural locations. 
However, no associations were found either between the BMI value and PA level, or between BMI value and SV duration, among the current study population.

\section{DISCUSSION}

In the current study, the preschool children spent longer duration of PA during weekends compared to weekdays. However, according to Brasholt et al. (2013), there was a diverse pattern of PA among preschool children during weekdays and weekends, where they were mostly more active during weekdays ${ }^{24}$. Moreover, Reilly (2010) found that preschool children in their study roughly engaged in approximately 2 to 3.5 hours of PA daily, and most of the activities were assumed to take place in preschools or childcare centers ${ }^{25}$. However, the current study relied on parents' information regarding the PA of their children. Thus, they might not be able to accurately report the PA of their children during school time. Inclusion of a PA record during school hours might be more informative.

Almost all preschool children in the current study were reported to spend $>2$ hours/day on SV (which included the duration of watching TV and using gadgets), with the average of 3.8 hours/day. Obviously, majority of them exceeded the international recommendation of $<2$ hours a day of screen time and the Malaysian Dietary Guideline's recommendation of $<2$ hours a day of sedentary activity. A study in Malaysia reported that children from rural areas were spending more time on screen viewing compared to children from urban areas ${ }^{11}$. However, the current study did not find any statistical difference of screen viewing duration between urban and rural areas. This might indicate that location may not be indicative of screen viewing duration among preschool children in Kuantan. With advancing technology nowadays, access to televisions, computers, smartphones, and tablets is ubiquitous. In Malaysia, about two-thirds $(66.5 \%)$ of the total population are reportedly smartphone users ${ }^{26}$.

Exceeding $>2$ hours of SV duration is also prevalent in other countries such as Hong Kong ${ }^{27}$, the United States $^{28}$, and Portugal ${ }^{29}$. Furthermore, a local study reported that the prevalence of Malaysian children who exceeded the recommended screen time $(68 \%)$ was found to be much higher than in the United States (44\%) or Australia (59\%) ${ }^{11}$. Therefore, the number of hours spent on screen viewing in Malaysia is worrying as it might promote sedentary lifestyle and potentially increase the risk of developing obesity due to reduced physical activity.

The current study did not manage to find any association between the BMI value and SV duration. Similarly, an experimental study found that TV viewing duration was unrelated to BMI among their study population of 91 adolescents (aged 13-15 years) ${ }^{30}$. On the hand, other studies have demonstrated positive associations between SV duration and $\mathrm{BMI}^{12,14,29}$. These inconsistent findings might be due to the different methods in classifying the BMI categories (i.e. by using the CDC growth charts versus the WHO growth standards). However, longer duration in SV is still one of the behaviors that could contribute to sedentary daily activities.

To the best of our knowledge, the current study was the first to assess the PA and SV durations among preschoolers in Kuantan, Pahang, comparing between its urban and rural locations. However, the cross-sectional study design limits the ability to evaluate causality. In addition, the PA and screen time were based on parental reports which might be exposed to under- or overreporting. There were also other confounding factors which might contribute to BMI such as food intake, the assessment of which should be included in future studies.

\section{CONCLUSION}

Preschoolers in Kuantan were largely found to have higher than the recommended SV duration and only two thirds meet the recommended PA duration, regardless of urban or rural locations. In addition, there was no difference found in terms of the BMI values between the rural and urban children. This suggests that the trend of sedentary lifestyle (particularly spending a lot of time watching TV and using tech devices) which may contribute to obesity development among this Gadget Generation, is found to be prevalent across different geographical areas in the state capital of Pahang. Therefore, interventions to increase the awareness regarding the duration of SV activities and its implication on children's health should be implemented in both urban and rural areas.

\section{FINANCIAL SPONSORSHIP Nil}

\section{CONFLICT OF INTEREST}

There is no conflict of interest declared with regards to the study. 


\section{REFERENCES}

1. World World Health Organization (2018). Taking Action on Childhood Obesity Report (WHO Ref No: WHO/NMH/PND/ECHO/18.1).

2. MN Ismail, AN Ruzita, AK Norimah, et al. (2009). Prevalence and trends of overweight and obesity in two crosssectional studies of Malaysian children, 2002-2008. In MASO 2009 Scientific Conference on Obesity: Obesity and our environment.

3. Reily JJ \& Kelly J (2011). Long-term impact of overweight and obesity in childhood and adolescence on morbidity and premature mortality in adulthood: Systematic review. Int J Obes (Lond). 35, 891-898.

4. Griffiths LJ, Parsons TJ \& Hill AJ (2010). Self-esteem and quality of life in obese children and adolescents: a systematic review. Int J Pediatr Obes. 5(4), 282-304.

5. National Association for Sport and Physical Education (NASPE) (2007). Physical activity guidelines for infants \& toddlers. Retrieved January 23, 2016, from

http://www.aahperd.org/naspe/templat e.cfm?template=toddlers. html

6. Müller AM, Khoo S \& Lambert R (2013). Review of physical activity prevalence of Asia school-age children and adolescents. Asia Pac J Public Health. 25(3), 227-238.

7. Institute for Public Health (2017). National Health and Morbidity Survey (NHMS) 2017: Adolescent Nutrition Survey 2017, Malaysia.

8. World Health Organization (2010). Global Recommendations on Physical Activity for Health.

https: / /www.who.int/dietphysicalactivit y/publications/9789241599979/en/ (assessed in July 2019).

9. Ministry of Health Malaysia (2013). Malaysian Dietary Guidelines for Children and Adolescent. Nutrition Division. Putrajaya, Malaysia.

10. Tremblay MS, Gray CE, Akinroye K, et al. (2014). Physical activity of children: A global matrix of grades comparing 15 countries. J Phys Act Health. 11(S1), S113-S125.
11. Lee ST, Wong JE, S Nik Shanita, et al. (2015). Daily Physical Activity and Screen Time, but Not Other Sedentary Activities, Are Associated with Measures of Obesity. Int J Environ Res Public Health. 12:146161.

12. Cox R, Skouteris $H$, Rutherford $L$, et al. (2012). Television viewing, television content, food intake, physical activity and body mass index: a cross-sectional study of preschool children aged 2-6 years. Health Promot J Austr. 23(1):58-62

13. Prentice-Dunn H \& Prentice-Dunn S (2012). Physical activity, sedentary behavior, and childhood obesity: A review of cross-sectional studies. Psychology, Health \& Medicine. 17(3):255-273.

14. de Jong E, Visscher TL, Hira Sing RA, et al. (2013). Association between TV viewing, computer use and overweight, determinants and competing activities of screen time in 4 - to 13-year-old children. Int J Obes. 37:47-53.

15. Ipsky LM \& lannotti RJ. (2012). Associations of television viewing with eating behaviors in the 2009 health behaviour in school-aged children study. Arch Pediatr. 166(5):465-472.

16. Pearson N \& Biddle SJ. (2011). Sedentary Behavior and Dietary Intake in Children, Adolescents, and Adults: A Systematic Review. Am J Prev Med. 41(2):178-188.

17. Olafsdottir S, Berg C, Eiben G, et al. (2014). Young children's screen activities, sweet drink consumption and anthropometry: Results from a prospective European study. Eur J Clin Nutr. 68:223-228.

18. Kremers JS, van-der-Horst $K$, \& Brug J. (2007). Adolescent screen-viewing behaviour is associated with consumption of sugar-sweetened beverages: The role of habit strength and perceived parental norms. Appetite. 48(3):345-350.

19. Halford JC, Gillespie J, Brown V, et al. (2004). Effect of television advertisements for foods on food consumption in children. Appetite. 42(2):221-225.

20. Halford JC, Boyland EJ, Hughes G, et al. (2007). Beyond-brand effect of television (TV) food advertisements/commercials on caloric intake and food choice of 5-7- 
year-old children. Appetite. 49(1):263267.

21. Sisson SB, Shay CM, Broyles ST, et al. (2012). Television-Viewing Time and Dietary Quality Among U.S. Children and Adults. Am J Prev Med. 43(2):196-200.

22. Poh BK, Ng B, Haslinda MD, et al. (2013). Nutritional status and dietary intakes of children aged 6 months to 12 years:findings of the Nutrition Survey of Malaysian Children (SEANUTS Malaysia). Br J Nutr. 110: S21-S35.

23. Centers for Disease Control and Prevention Recommended BMI-for-age Cutoffs 2004. https://www.cdc.gov/nccdphp/dnpao/g rowthcharts/training/bmiage/page4.htm I (Accessed on July 20th, 2020).

24. Brasholt M, Chawes B, Kreiner-Moller E, et al. (2013). Objective assessment of levels and patterns of physical activity in preschool children. International Pediatric Research Foundation. 15:969.

25. Reilly JJ. (2010). Low levels of objectively measured physical activity in preschoolers in childcare. Med Sci Sports Exerc. 42(3):502-507.

26. Global Mobile Market Report (2017-2022). https: //resources.newzoo.com/hubfs/Fa ctsheets/Newzoo_The_Global_Mobile_Ma rket_Report_Fact_Sheet.pdf (Accessed on July 20th, 2020).
27. Mak YW, Wu CST, Hui DWS, et al. (2014). Association between screen viewing duration and sleep duration, sleep quality, and excessive daytime sleepiness among adolescents in Hong Kong. Int J Environ Res Public Health. 11(11):1120111219.

28. Fakhouri TH, Hughes JP, Brody DJ, et al. (2013). Physical activity and screen-time viewing among elementary school-aged children in the United States from 2009 to 2010. JAMA Pediatrics. 167(3):223-229.

29. Jago R, Stamatakis E, Gama A, et al. (2012). Parent and Child Screen-Viewing Time and Home Media Environment. Am J Prev Med. 43(2):150-158.

30. Bickham DS, Blood EA, Walls CE, et al. (2013). Characteristics of screen media use associated with higher BMI in young adolescents. Pediatrics. 131(5):935-941.

31. Stamatakis E, Coombs N, Jago R, et al. (2013). Associations between indicators of screen time and adiposity indices in Portuguese children. Preventive Medicine. 56:299-303. 